\title{
Damage evolution law on the surface field of argillaceous dolomite based on Brazilian test and 3D digital image correlation
}

\author{
Delei Yang \\ Department of Architectural and Civil Engineering, University of Huanghuai, Zhumadian 463000, China \\ Department of Civil Engineering, University of Ottawa, NO.75 Laurier Avenue, N K1N 6N5, Canada \\ muyi20071001@126.com
}

Xiaochuan Wang

School of civil engineering, Guizhou University, Guiyang 550025, China

\begin{abstract}
This paper aims to disclose the damage evolution law of the surface field of argillaceous dolomite. For this purpose, the 3D digital image correlation was combined with the Brazilian test into a new analysis method for the surface field damage evolution of the rock. First, the stress-strain curve of argillaceous dolomite was obtained in Brazilian test, and the strain contours of the key points were acquired by 3D digital image correlation. Then, the standard deviations of the $\mathrm{x}$ and $\mathrm{y}$ direction strains at the key points during the test were calculated using statistical methods. In addition, the dual damage factor was introduced to quantify the law of the strain statistics and plotted into a curve. Finally, the strains in $\mathrm{x}$ and $\mathrm{y}$ directions on the horizontal axis ox in the disc center were obtained through elastic mechanical analysis and compared with those measured by 3D digital image correlation in the elastic phase. In this way, the following conclusions were drawn: the argillaceous dolomite exhibited obvious non-homogeneity in the surface field damage evolution. The different phases of the Brazilian test can be determined accurately according to the turning points of the damage factor curve. The fluctuations of the damage factor curve also reveal the features of surface field damage evolution of argillaceous dolomite in Brazilian test. This research shows that the traditional assumption of homogeneity cannot reflect the heterogeneity of the surface field damage evolution of argillaceous dolomite in Brazilian test and provides a quantitative research method for rock damage evolution in that test.
\end{abstract}

KEYWORDS. Brazilian test; 3D digital image correlation; Surface field; Damage evolution.

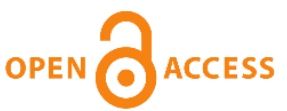

Citation: Yang, D.L., Wang, X.C.., Damage evolution law on the surface field of argillaceous dolomite based on Brazilian test and 3D digital image correlation, Frattura ed Integrità Strutturale, 48 (2019) 144-151.

Received: 07.11.2018

Accepted: 02.02 .2019

Published: 01.04.2019

Copyright: (C) 2019 This is an open access article under the terms of the CC-BY 4.0, which permits unrestricted use, distribution, and reproduction in any medium, provided the original author and source are credited. 


\section{INTRODUCTION}

$\checkmark$ r There are many defects in natural rocks, such as microcracks and voids. Under external loads, these defects will evolve continuously and coalesce into macrocracks, a precursor to rock damage and destruction. Much theoretical research has been done on the initiation, propagation and coalescence laws of cracks in rocks, yielding fruitful results on the damage evolution mechanism of rocks [1,2]. Nevertheless, the existing theoretical models are not mature enough, making it necessary to perform experimental observations. In 1978, the International Society for Rock Mechanics recommended the Brazilian test as a method for measuring rock tensile strength [3]. In Brazilian test, the rock failure is ultimately caused by tensile damage, for the tensile stress at the centre of the disc is $1 / 3$ of the compressive stress [4] and compressive strength of the rock is generally $8 \sim 10$ times the tensile strength [5]. The traditional procedure of Brazilian test is as follows: paste a strain gauge at the centre of the disc vertically to the loading direction, measure the strain in the central tensile region, and compute the tensile modulus of the rock. There are several deficiencies with the traditional procedure [6 9]: First, the strain gauge must be pasted right at the centre and parallel to the tensile direction, and the length of the gauge should not exceed $1 / 10$ of the disc diameter; otherwise, the measured strain will be less than the true strain at the centre of the disc. Second, the rock is assumed to be homogenous, which is unlikely in reality. Third, the traditional method may not always acquire enough data for further analysis.

In fact, rock exists inhomogeneity, and damage and failure process under external force is difficult to predict. Traditional methods study the damage evolution process of inhomogeneous rocks by measuring the stress-strain characteristics of individual points, which can not truly reflect the whole damage evolution process of inhomogeneous rocks. To solve these defects and to study accurately the law of rock damage evolution, we need to study the surface field of rock damage evolution process, the digital image correlation has been proposed and applied to examine the damage evolution and destruction of rocks under external loads [10]. For instance, Ma Shaopeng [11] described the damage evolution of rocks using digital image correlation. Zhao Cheng et al. [12] adopted the same method to study the deformation failure of pre-cracked rocks under uniaxial compression. Dai Shuhong et al. [13] put forward a test method to determine the crack tip location and stress intensity factor of Grade I II rocks based on digital image correlation. Ji Weihong et al. [14] employed digital image correlation to ascertain the strain field of two different types of rock fractures, and determined the critical features and process length of the rock failures. Zhang et al. [15 18] investigated the damage evolution mechanism and strain localization features of rock under cyclic and concentrated load by digital image correlation. Gao Yue [19] proposed a 3D digital image correlation approach, which overcomes the following problems of 2D digital image correlation: the axis of the camera must be vertical to the surface of the measured object, and the object surface must be flat and with no significant out-of-plane displacement.

Argillaceous dolomite is a rock with complex mineral components and fine grains. Under external loads, microcracks may appear and propagate on argillaceous dolomite, and even penetrate through the rock. It is difficult to characterize the damage evolution of the rock by the traditional procedure of Brazilian test. To disclose this process of inhomogeneous argillaceous dolomite, this paper combines the 3D digital image correlation and the Brazilian test into a new analysis method for the surface field damage evolution of the rock.

\section{METHODOLOGY}

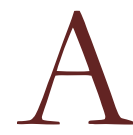

ccording to the Specification for Rock Tests in Water Conservancy and Hydroelectric Engineering (SL264-2001), the argillaceous dolomite with a diameter of $50 \mathrm{~mm}$ and a height of $50 \mathrm{~mm}$ was selected as the test specimen. The main mineral components of the specimen are $\mathrm{SiO}_{2}(50 \% \sim 70 \%)$ and $\mathrm{Al}_{2} \mathrm{O}_{3}(15 \% \sim 20 \%)$. In addition, the specimen also contains a small amount of $\mathrm{Fe}_{2} \mathrm{O}_{3}, \mathrm{FeO}$ and $\mathrm{CaO}$.

The RMT-301 loading system developed by the Institute of Rock and Soil Mechanics, Chinese Academy of Sciences was adopted for our test. The RMT-301, as the most advanced rock and concrete mechanics test system in China, is specially designed for mechanical properties test of engineering materials such as rock and concrete. The system has complete test functions, easy operation, high automation and high accuracy to meet the requirements of national indicators. The system consists of an axial displacement sensor (measuring range: $50 \mathrm{~mm}$; accuracy: $3 \% 0$ ), an axial force sensor (measuring range: $100 \mathrm{kN}$; accuracy: $5 \%$ ) and a lateral displacement sensor (measuring range: $2.5 \mathrm{~mm}$; accuracy: $2 \% 0$ ). To simulate the entire process of crack initiation and propagation, the load was applied constantly at the rate of $0.01 \mathrm{~mm} / \mathrm{s}$ using displacement control. A 5 million-pixel industrial camera (focal length: $50 \mathrm{~mm}$; accuracy: $0.23 \mu \mathrm{m}$ ) was employed to collect the test images of the specimen. In theory, the higher the pixels of industrial cameras, the higher the accuracy of the three-dimensional 
digital image correlation method. Then, too high accuracy has little significance for the final calculation results. The industrial cameras with 5 million pixels used in this experiment have fully met the accuracy requirements of the experiment. The camera was controlled by software synchronous triggering, and the shooting frequency was set to $1 \mathrm{frame} / \mathrm{second}$, aiming to record the entire damage process of the specimen. In addition, a $15 \times 13$ calibration plate (pitch: $4 \mathrm{~mm}$ ) was adopted, considering the features of 3D digital image correlation.

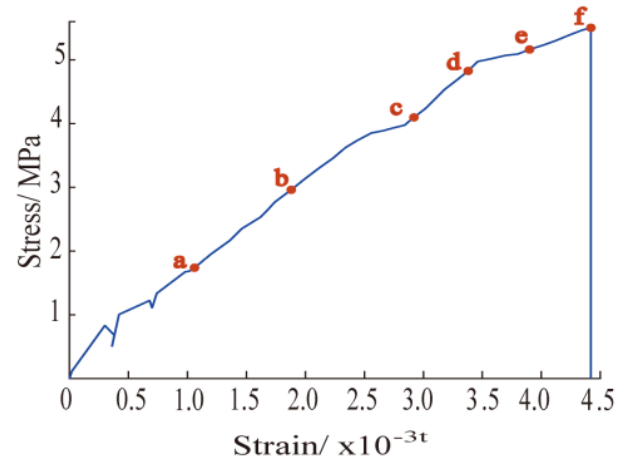

Figure 1: Stress-strain curve in Brazilian test.

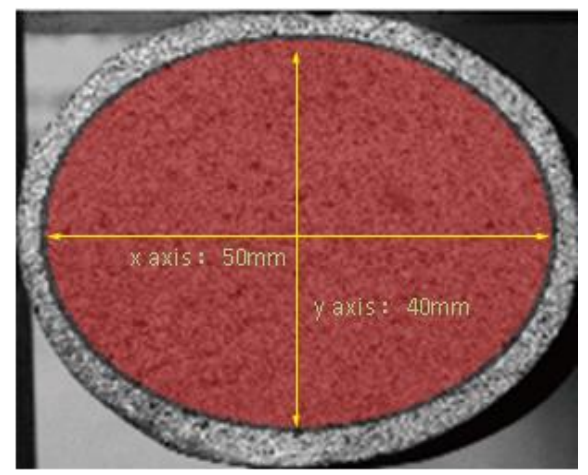

Figure 2: Calculation area of the surface field.
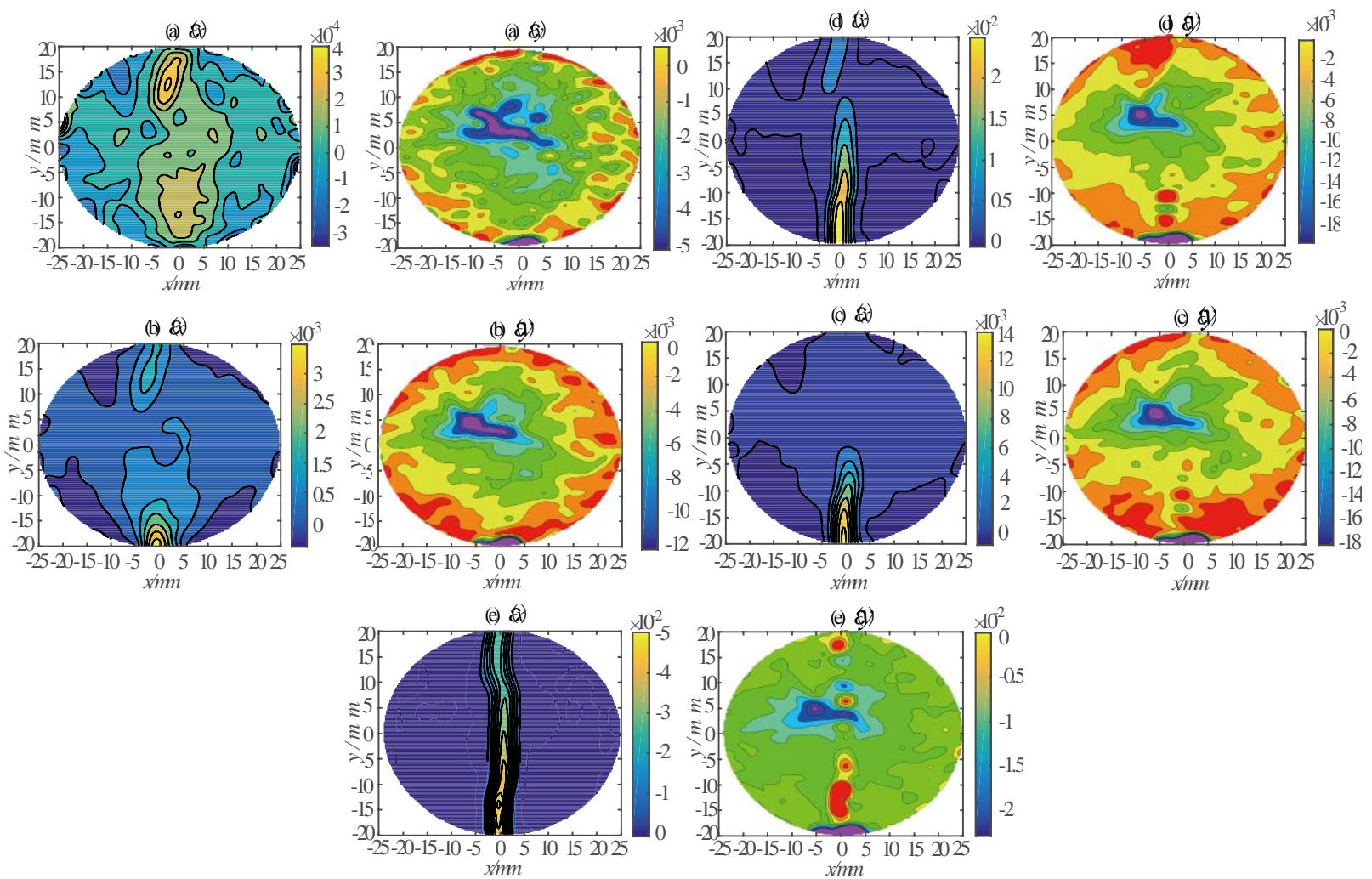

Figure 3: Damage evolution of surface strain field in Brazilian test.

\section{RESUlts AND ANALYSIS}

\section{Damage evolution law of surface field}

T $\mathrm{n}$ the process of studying rock deformation and failure, scholars have deeply studied and analyzed the crack initiation, propagation law and damage evolution mechanism in rock from the angles of theory, model test and numerical analysis, and have achieved a lot of results[1,2,11,13]. Based on previous research results and experimental data of this experiment, the stress-strain curve of the specimen was plotted along the loading direction in the Brazilian test (Fig. 1). 
Referring to the previous research, points a e were selected as the key points in the loading process. The calculation area of the surface field was determined before discussing the damage evolution of argillaceous dolomite throughout the test. Previous studies have shown that the calculation area should be as large as possible, but should not reach the edge of specimen surface due to factors like lens distortion [20]. Thus, the calculation area selected for our test is $50 \mathrm{~mm}$ long along the $\mathrm{x}$-axis and $40 \mathrm{~mm}$ long along the $\mathrm{y}$-axis (Fig. 2). Within this area, the strain contours in the $\mathrm{x}$ and $\mathrm{y}$ directions corresponding to the key points a e were obtained by image correlation (Fig. 3). During the calculation, the tensile strain was positive and the compressive strain was negative.

As shown in Figs. 1 and 3, the stress-strain curve of argillaceous dolomite in Brazilian test falls into four distinct phases: the compaction phase (curve segment $\mathrm{o} \sim \mathrm{a}$ ), the elastic phase (curve segment $\mathrm{a} \sim \mathrm{b}$ ), the elastic-plastic phase (curve segment $\mathrm{b} \sim \mathrm{c}$ ), and the plastic phase (curve segment $\mathrm{c} \sim \mathrm{e}$ ). Below is a detailed description of all four phases.

In the first phase, the compression in the y direction caused the collapse of some large voids and the closure of some initial microcracks, while the tension in the $\mathrm{x}$ direction induced an increase in the number of voids and the further opening of the initial defects. This phase is marked by instability, jumping and fluctuation resulted from the uneven distribution of microcracks in argillaceous dolomite. According to the strain contours in the $\mathrm{x}$ and y directions (Fig. 3a), all the strains in the $\mathrm{y}$ direction and most of those in the $\mathrm{x}$ direction were compressive, and some areas were stretched. These phenomena are closely related to the uneven distribution of voids and microcracks in the rock.

In the second phase, the strains in the $\mathrm{x}$ and $\mathrm{y}$ directions were linearly correlated, despite the heterogeneity of the argillaceous dolomite. As shown in Fig. 3b, the strains in the $\mathrm{x}$ direction shifted from the disordered state in the compaction phase to the ordered state in the elastic phase; the surface strain of the entire disc was relatively uniform, without large strain concentration. By contrast, the strains in the y direction were still disordered. The strain gradually decreased from the centre to the edge, forming an annular contour. The peak strain appeared at the top left of the centre, owing to the heterogenous distribution of internal defects.

In the third phase, the initial microcracks propagated, new microcracks emerged, and internal damages began to appear. The strains further increased with the increase in load. Despite the steady development of microcracks, there was no coalescence of macro or microcracks. Near the end of this phase, a strain concentration area appeared at the bottom and expanded upwards.

In the fourth phase, the macro and microcracks began to expand, leading to the unstable expansion of crack damage on the specimen [21]. From the strain contours of points $\mathrm{d}$ and e, it can be seen that the strain concentration area penetrated along the loading direction, forming a huge vertical macrocrack. Thus, the argillaceous dolomite specimen broke into pieces.

The above analysis shows that the argillaceous dolomite, as a soft rock, has a low tensile strength. The specimen exhibited obvious non-homogeneity in the surface field damage evolution through the Brazilian test. The strain concentration in the $\mathrm{x}$ direction started from the bottom and gradually expanded along the loading direction, while that at the top of the rock appeared in the plastic phase. Then, the top and bottom concentration areas moved towards each other and eventually converged into a band along the loading direction, pushing the stress to its peak value. In the y direction, the strain field was always nonhomogeneous and the strains were always disordered.

\section{Strain statistics}

This subsection aims to further disclose the law of surface field damage evolution in the specimen. Considering both computing accuracy and efficiency, the $\mathrm{x}$ - and y direction strain fields of 20,588 scattered spots in each digital image acquired in Brazilian test were statistically divided into an average of 20 groups.

The strain statistics at points a e are given in Figs. 4 and 5, in which the $\mathrm{x}$-axis shows the 20 statistical data for each group and the y-axis shows the mean value of each group. Fig. 4 reveals a gradual increase of the tensile strains in the $\mathrm{x}$ direction, and a decrease in the proportion of stretched areas; this is because some areas were always compressed horizontally due to the complex voids and defects within the rock. With the increase of the load, the strains were relatively large in some areas and uniform in the other areas. As shown in Fig. 5, the absolute value of the compressive strains in the y direction was gradually on the rise, the crack propagation was unstable after entering the elastic-plastic phase, and some areas seemed to be stretched.

\section{Dual damage factors}

The dual damage factors $K_{1}$ and $K_{2}$ were introduced to quantify the law of the strain statistics in Figs. 4 and 5 . The factor can be expressed as:

$$
K_{1}=\sqrt{\frac{1}{n-1} \sum_{i=1}^{n}\left(\varepsilon_{x i}-\bar{\varepsilon}_{x}\right)}
$$




$$
K_{2}=\sqrt{\frac{1}{n-1} \sum_{i=1}^{n}\left(\varepsilon_{y i}-\bar{\varepsilon}_{y}\right)}
$$

where $\varepsilon_{\mathrm{xi}}$ and $\varepsilon_{\mathrm{yi}}$ are respectively the strain values in $\mathrm{x}$ and $\mathrm{y}$ directions at each point in the strain field. The mean values $\bar{\varepsilon}_{\mathrm{x}}$ and $\overline{\varepsilon_{y}}$ can be expressed as:

$$
\begin{aligned}
& \overline{\varepsilon_{x}}=\frac{1}{n} \sum_{i=1}^{n} \varepsilon_{x i} \\
& \overline{\varepsilon_{y}}=\frac{1}{n} \sum_{i=1}^{n} \varepsilon_{y i}
\end{aligned}
$$
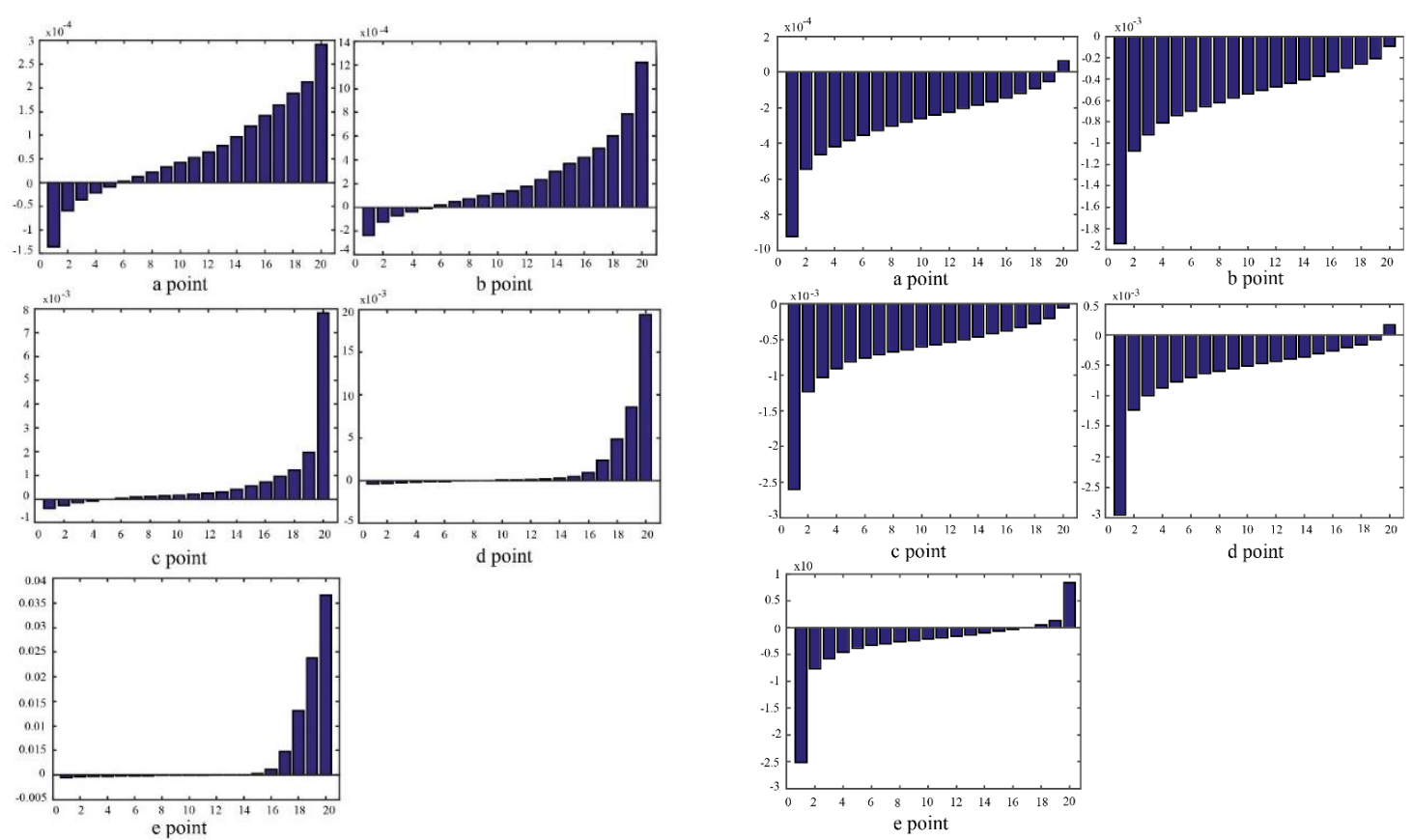

Figure 4: Horizontal strain statistics

Figure 5: Vertical strain statistics

The dual damage factors $K_{1}$ and $K_{2}$ are collectively referred to the damage factor $K$ below.

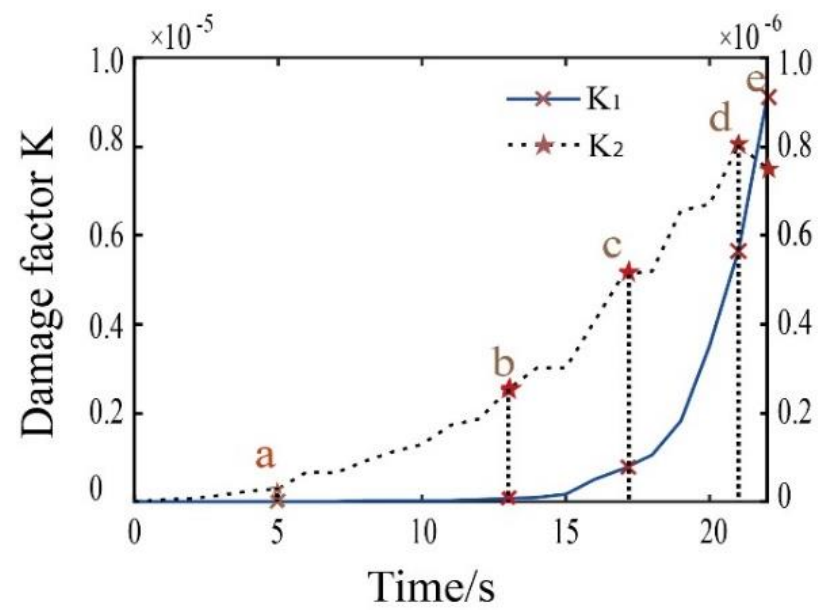

Figure 6: Damage factor curve. 
Fig. 6 shows the variation in the damage factor over time. Under the small tensile stress in the compaction phase, the strain field variation obeyed the random distribution in the $\mathrm{x}$ direction, showing no obvious strain concentration. Hence, the dispersion in the $\mathrm{x}$ direction was relatively small and $\mathrm{K}$ was almost zero, while strain field variation increased steadily in the $\mathrm{y}$ direction. In the elastic phase, the strain field was relatively stable in the $\mathrm{x}$ direction, and the strain field variation still increased steadily in the y direction. This is because the strains in the y direction declined from the centre to both sides. At the end of the elastic phase, the slope of the standard deviations in the $\mathrm{x}$ and $\mathrm{y}$ directions began to increase, indicating a prominent damage evolution across the surface field.

Comparing Fig. 1 and Fig. 6, the stress-strain curve agrees well with the damage factor curve in different phases. Thus, the different phases of the Brazilian test can be determined accurately according to the turning points of the damage factor curve, rather than empirical judgement based on the stress-strain curve. The fluctuations of the damage factor curve also reveal the features of surface field damage evolution of argillaceous dolomite in Brazilian test.

\section{Comparison between analysis results and test results}

This subsection compares the test data with the results of the elastic mechanical analysis [22] on the surface strain of argillaceous dolomite. According to the elastic mechanical analysis of the plane stress problem, the stress-strain relationship at any point on the $\mathrm{x}$-axis vertical to the loading direction in the disc plane can be obtained by:

$$
\begin{aligned}
& \sigma_{x}=\frac{2 P}{\pi D L}\left[\frac{16 D^{2} x^{2}}{\left(4 x^{2}+D^{2}\right)^{2}}-1\right] \\
& \sigma_{y}=\frac{2 P}{\pi D L}\left[\frac{4 D^{2} x}{\left(4 x^{2}+D^{2}\right)^{2}}-1\right]
\end{aligned}
$$

where $-0.5 \mathrm{D} \leqq \mathrm{x} \leqq 0.5 \mathrm{D} ; \mathrm{D}$ is disc diameter.

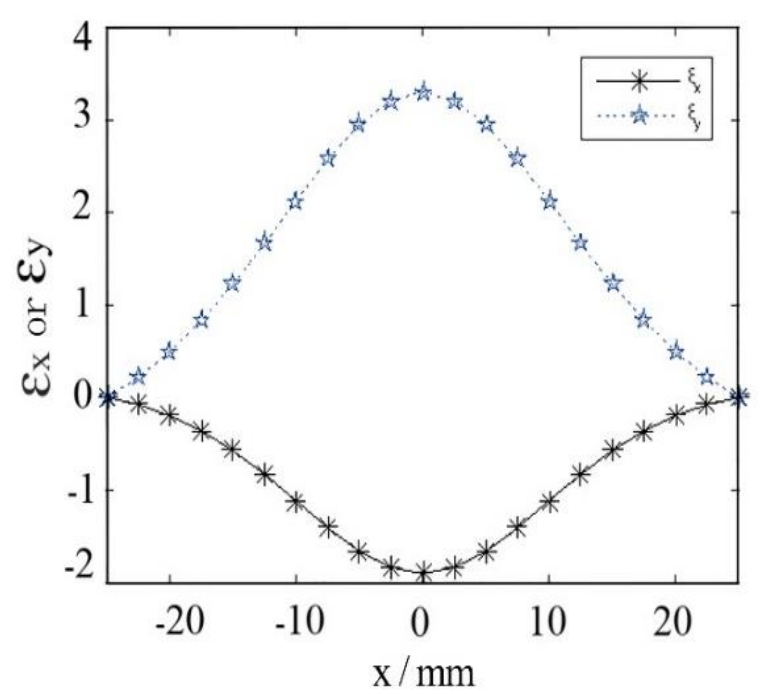

Figure 7: The analytic strains in $\mathrm{x}$ and $\mathrm{y}$ directions on the horizontal axis ox in the disc centre.

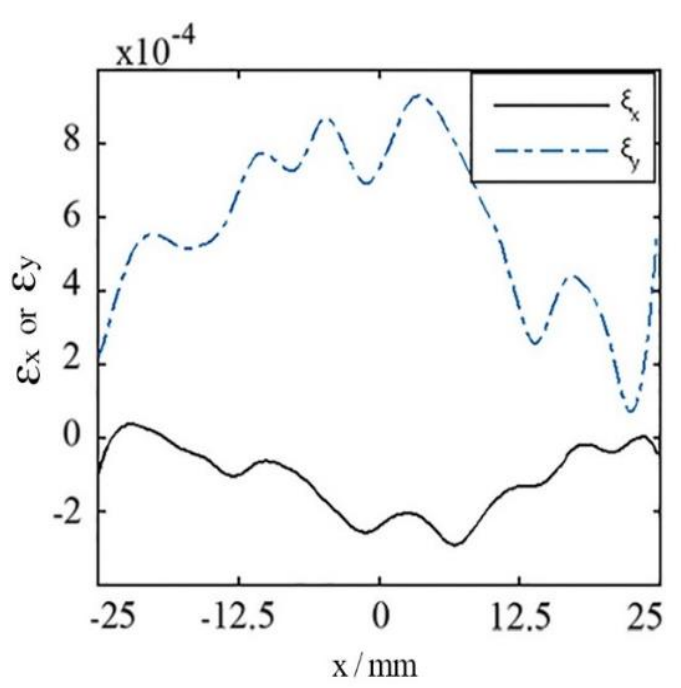

Figure 8: Measured strains in $\mathrm{x}$ and $\mathrm{y}$ directions on the horizontal axis ox in the disc centre.

According to elastic mechanics, the strains at any point of $\mathrm{x}$ in $(\mathrm{x}, 0) \mathrm{x}$ and $\mathrm{y}$ directions are as follows:

$$
\begin{aligned}
& \varepsilon_{x}=-\frac{\sigma_{x}-\mu \sigma_{y}}{E}=-\frac{2 P}{\pi D L E} . \\
& \left\{\left[\frac{16 D^{2} x^{2}}{\left(4 x^{2}+D^{2}\right)^{2}}-1\right]-\mu\left[\frac{4 D^{2} x}{\left(4 x^{2}+D^{2}\right)^{2}}-1\right]\right\}
\end{aligned}
$$




$$
\begin{aligned}
& \varepsilon_{y}=\frac{\sigma_{y}-\mu \sigma_{x}}{E}=\frac{2 P}{\pi D L E} . \\
& \left\{\left[\frac{16 D^{2} x}{\left(4 x^{2}+D^{2}\right)^{2}}-1\right]-\mu\left[\frac{16 D^{2} x^{2}}{\left(4 x^{2}+D^{2}\right)^{2}}-1\right]\right\}
\end{aligned}
$$

where $\mathrm{E}$ is the tensile modulus; $\mathrm{P}$ is the linear load; $\mu=0.2$ is the Poisson's ratio.

The strains in $\mathrm{x}$ and $\mathrm{y}$ directions on the horizontal axis ox in the disc centre were obtained through elastic mechanical analysis and plotted in Fig. 7. The same strains were measured by 3D digital image correlation in the elastic phase and recorded in Fig. 8. As shown in the two figures, the curves shared a similar trend; however, a great difference between the measured and analytical strains was observed in the linear elastic phase at both ends of the a-axis. The difference is attributable to the end strains of the specimen induced by the compression of other parts during the test, which is, in turn, caused by the heterogeneity of the argillaceous dolomite. This contradicts the assumption of homogeneity in traditional procedure of the Brazilian test.

\section{ConClusions}

This paper explores the damage evolution law of surface field on argillaceous dolomite through 3D digital image correlation and Brazilian test. For this purpose, the 3D digital image correlation was combined with the Brazilian test into a new analysis method for the surface field damage evolution of the rock. First, the stress-strain curve of argillaceous dolomite was obtained in Brazilian test, and the strain contours of the key points were acquired by 3D digital image correlation. Then, the standard deviations of the $\mathrm{x}$ and $\mathrm{y}$ direction strains at the key points during the test were calculated using statistical methods. In addition, the dual damage factor was introduced to quantify the law of the strain statistics and plotted into a curve. Finally, the strains in $\mathrm{x}$ and $\mathrm{y}$ directions on the horizontal axis ox in the disc center were obtained through elastic mechanical analysis and compared with those measured by 3D digital image correlation in the elastic phase. The main conclusions are as follows:

(1) The argillaceous dolomite, as a soft rock with low tensile strength, exhibited obvious non-homogeneity in the surface field damage evolution. The strain concentration in the $\mathrm{x}$ direction started from the bottom and eventually formed a strain concentration band along the loading direction before the penetration of macrocracks. In the y direction, the strains were always disordered.

(2) After statistically grouping the strain data of 3D digital image correlation, it is learned that the tensile strain increased gradually along the $\mathrm{x}$ direction throughout the Brazilian test, but the proportion of stretched areas decreased; this is because some areas were always compressed horizontally due to the complex voids and defects within the rock. With the increase of the load, the strains were relatively large in some areas and uniform in the other areas. Moreover, the absolute value of the compressive strains in the y direction was gradually on the rise, the crack propagation was unstable after entering the elastic-plastic phase, and some areas seemed to be stretched.

(3) The different phases of the Brazilian test can be determined accurately according to the turning points of the damage factor curve, rather than empirical judgement based on the stress-strain curve. The fluctuations of the damage factor curve also reveal the features of surface field damage evolution of argillaceous dolomite in Brazilian test.

(4) The strains in $\mathrm{x}$ and $\mathrm{y}$ directions on the horizontal axis ox in the disc centre were obtained through elastic mechanical analysis, and the same strains were measured by 3D digital image correlation in the elastic phase. Comparison shows that the curves of the analytical and measured strains shared a similar trend; however, a great difference between the measured and analytical strains was observed in the linear elastic phase at both ends of the a-axis. The difference is attributable to the end strains of the specimen induced by the compression of other parts during the test, which is, in turn, caused by the heterogeneity of the argillaceous dolomite. This contradicts the assumption of homogeneity in traditional procedure of the Brazilian test.

\section{ACKNOWLEDGMENT}

he authors wish to thank the Natural Science Foundation of China for financially supporting the research in the paper through the grant NO.51478334 and Henan Science and Technology Department supporting the research in the paper through the grant NO.182102310918. 


\section{REFERENCES}

[1] Marcu, T., Todea, M., Maines, L., Leordean, D., Berce, P. Popa, C. (2012). Metallurgical and mechanical characterisation of titanium based materials for endosseous applications obtained by selective laser melting, Powder Metallurgy, 55(4), pp.309-314.

[2] Huang, C.S., Zhang, Z.F., Dao, D.Y. (2018). Thermal stress restrained specimen test on fiber enhanced asphalt concrete and thermal stress calculation models, Annales de Chimie - Science des Matériaux, 42(3), pp.387-403.

[3] Bieniawski, Z. T., Hawkes, I. (1978). Suggested method for determining tensile strength of rock materials, International Journal of Rock Mechanics and Mining Sciences and Geo-Mechanics Abstracts, 15(3), pp.99-103.

[4] Hondros, G. (1959). The evaluation of Poisson's ratio and the modulus of materials of a low tensile resistance by the Brazilian (indirect tensile) test with particular reference to concrete, Australian Journal of Applied Sciences, 10(3), pp.243-268.

[5] Gong, F. Q., Li, X. B., Zhao, J. (2010). Analytical algorithem to estmate tenile modulus in barazilan disk spliting tests, Chinese Journal of Rock Mechanics and Engineering, 29(5), pp.881 -891.

[6] Zhao, J., Li, H. B. (2000). Experimental determination of dynamic tensile properties of granite, International Journal of Rock Mechanics and Mining Sciences, 37(5), pp.861-866.

[7] Marino, C., Nucara, A., Pietrafesa, M. (2018). Evaluation of the direct and diffused component of solar radiation starting from global radiation measurements: Preliminary analysis, Mathematical Modelling of Engineering Problems, 5(4), pp.317-322.

[8] Tao, T.J., Huang, P., Wang, S.P., Luo, Y. (2018). Safety evaluation of blasting fly-rock based on unascertained measurement model, Instrumentation Mesure Métrologie, 17(1), pp.55-62.

[9] Liu, F. Z. (1996). Study of mechanical properties of rock in tension and tension-shear states, Journal of Yangtze Riverentific Research Institute, 13(3), pp.35-39.

[10] Peters, W. H., Ranson, W. F. (1982). Digital Imaging Techniques in Experimental Stress Analysis, Optical Engineering, 21(3), pp.427-431.

[11] Ma, S. P., Zhou, H. (2006). Study on the evolution characteristics of surface strain field during the process of rock failure, Chinese Journal of Rock Mechanics and Engineering, 25(3), pp.590-595.

[12] Zhao, C., Tian, J., Matsuda, H., Bao, C. (2015). Crack propagation and damage of rock under uniaxial compression based on global strain field analysis, Chinese Journal of Rock Mechanics and Engineering, 34(4), pp.763-769.

[13] He, L.L., Zhu H., Gao, Z.X. (2018). A novel asphalt pavement crack detection algorithm based on multi-feature test of cross-section image, Traitement du Signal, 35(3-4), pp.289-302.

[14]Ji, W., Pan, P., Miao, S., Su, F. S., Du, M. P. (2016). Fracture characteristics of two types of rocks based on digital image correlation, Rock and Soil Mechanics, 37(8), pp.2329-2305.

[15] Zhang, H., Huang, G. Y., Song, H. P., Kang, Y. L. (2013). Experimental characterization of strain localization in rock, Geophysical Journal International, 194, pp.1554-1558.

[16] Zhang, H., Song, H. P., Kang, Y. L., Huang, G. Y., Qu, C. Y. (2012). Experimental Analysis on Deformation Evolution and Crack Propagation of Rock Under Cyclic Indentation, Rock Mechanics and Rock Engineering, 46, pp.1053-1059.

[17] Zhang, H., Huang, G. Y., Song, H. P., Kang, Y. L. (2012). Experimental investigation of deformation and failure mechanisms in rock under indentation by digital image correlation, Engineering Fracture Mechanics, 9, pp.667-675.

[18] Zhang, H., Fu, D. H., Song, H. P., Kang, Y. L., Huang, G. Y., Qi, G., Li, J. Y. (2014). Damage and Fracture Investigation of Three-Point Bending Notched Sandstone Beams by DIC and AE Techniques, Rock Mechanics \& Rock Engineering, 48(3), pp.1297-1303.

[19] Gao, Y. (2014). Research on key technologies and application of three-dimensional digital image correlation method, HeFei: University of Science and Technology of China.

[20] Liu, X. Y. (2012). Digital image correlation method and its application on mechanical properties measurement or materials, Changchun: Jilin University.

[21] Cai, M. F. (2015). Rock mechanics and Engineering (Second Edition), Beijing: Science Press.

[22] Xu, Z. L. (1960). Elasticity theory, Beijing: People's Education Press. 